Eastern Illinois University

The Keep

Faculty Research and Creative Activity

Economics

January 2013

\title{
International stock markets response to the Federal Reserve policy actions: the case of emerging MENA markets
}

Ahmed Abou-Zaid

Eastern Illinois University, asabouzaid@eiu.edu

Follow this and additional works at: http://thekeep.eiu.edu/economics_fac

Part of the Business Commons

\section{Recommended Citation}

Abou-Zaid, Ahmed, "International stock markets response to the Federal Reserve policy actions: the case of emerging MENA markets" (2013). Faculty Research and Creative Activity. 9.

http://thekeep.eiu.edu/economics_fac/9

This Article is brought to you for free and open access by the Economics at The Keep. It has been accepted for inclusion in Faculty Research and Creative Activity by an authorized administrator of The Keep. For more information, please contact tabruns@eiu.edu. 


\title{
International stock markets response to the Federal Reserve policy actions: the case of emerging MENA markets
}

\begin{abstract}
Ahmed S. Abou-Zaid
Eastern Illinois University, 600 Lincoln Avenue, Charleston IL 61920, USA

E-mail: asabouzaid@eiu.edu

Abstract: Understanding the impact of external shocks on stock markets returns and volatility is crucial for market participants as volatility is synonymous with risk. The focus of this paper is to determine whether the US monetary policy decisions influence the stock market returns and volatility in Egypt, Israel, and Turkey. Efficient markets react to new information; hence a greater response would be expected in terms of trading activity if there is an unanticipated element to any information revealed. Thus, the paper decomposes the monetary policy shocks into both expected and surprise components and test their influence on the MENA stock markets. Adopting a multivariate GARCH technique, the results suggest a significant effect of the US monetary shocks on Cairo Stock Exchange but not Tel-Aviv and Istanbul stock exchanges. Moreover, the effect of the anticipated monetary policy actions on expected returns account for the largest part of the response of the stock prices.
\end{abstract}

Keywords: monetary policy shock; emerging stock markets; Middle East and North Africa; MENA; volatility transmission; GARCH.

\begin{abstract}
Reference to this paper should be made as follows: Abou-Zaid, A.S. (2013) 'International stock markets response to the Federal Reserve policy actions: the case of emerging MENA markets', Int. J. Financial Markets and Derivatives, Vol. 3, No. 2, pp.179-190.

Biographical notes: Ahmed S. Abou-Zaid is an Associate Professor of Economics at Eastern Illinois University. He has taught economics in both the US and Egyptian universities. He has published several articles in exchange rate, trade, economic growth, volatility spillover, and international stock markets.
\end{abstract}

\section{Introduction}

The ultimate objectives of monetary policy are expressed in terms of macroeconomic variables such as output, employment, and inflation. However, the influence of monetary policy instruments on these variables is at best indirect. The most direct and immediate effects of monetary policy actions, such as change of interest rates, are on the financial markets. By affecting asset prices and returns, policymakers try to modify economic behaviour in ways that will help to achieve their ultimate objectives (Bernanke and Kuttner, 2005). 
Stock prices are among the most closely watched prices in any economy and are viewed as being highly sensitive to economic conditions. They have also been known to swing rather widely, leading to concerns about possible deviations of stock prices from fundamental values that may have adverse implications for the economy. Thus, it is very important to know more precisely how monetary policy and the stock market are related.

This relationship between monetary policy and stock prices has recently received increasing attention in financial research. The conventional view suggests that a tight monetary policy serves as bad news for the stocks as it is generally associated with higher future interest rates and decreases in the level of economic activity. In contrast, an expansive monetary policy is commonly viewed as good news as these periods are usually associated with lower future interest rates and increases in economic activity (Conover et al., 1999).

Different studies have examined the relationship between US monetary policy and US stock prices, but the effect of the US monetary policy on foreign stock prices has not been extensively pursued. This cross-border relation has become a crucial issue to study, notably with increasing global financial integration. This integration was often strengthened through the formation of free trade areas or increasing trade volume among countries.

The US is considered one of the largest trading partners for Egypt, Israel, and Turkey. The USA is Israel's largest trade partner; it accounts for $36.7 \%$ of Israel's exports ( $\$ 11$ billion) and 29.2\% (\$10.9 billion) of Israel's imports. As for Egypt, the USA comes as the second trade partner after EU countries, at which it constitutes $28.1 \%$ of Egypt's trade with foreign countries. Note that the USA has committed itself, after signing the peace treaty between Egypt and Israel in 1979, to pay an annual financial aid to Egypt and Israel equal to $\$ 8$ billion. This puts Egypt and Israel at the top of the list of the countries that receive aid from the USA. Moreover, in December 2004, Egypt, Israel, and the USA signed a protocol to set up seven qualified industrial zones (QIZs), where goods would gain free access to US markets provided that $35 \%$ of their inputs come from cooperation between Egyptian and Israeli companies. This constitutes an advanced step towards a free trade pact between the USA and Egypt.

As for Turkey, the USA accounts for $6.67 \%$ ( $\$ 4.9$ billion) of Turkey's total exports and $4.6 \%$ ( $\$ 5.3$ billion) of total imports (Halicioglu, 2007). This places the USA as the second trade partner after the European Union.

The focus of this paper is to examine the influence of US monetary policy decisions on both returns and volatility of the selected emerging MENA markets of Egypt, Israel, and Turkey. Following Bredin et al. (2005), this paper focuses on two aspects of transmission of news with respect to monetary policy.

First, do regularly scheduled meetings of the Federal Open Market Committee (FOMC) have an influence on the volatility of the selected emerging stock markets? Second, markets react to new information; hence a greater response would be expected in terms of trading activity if there is an unanticipated element to any information revealed. How do emerging stock market returns and volatility respond to surprises in US monetary policy?

This study represents the first attempt to address possible causes of volatility spillovers for the case of Egypt's, Israel's, and Turkey's stock markets.

The remainder of this paper is organised as follows. Section 2 reviews the previous literature. Section 3 describes the methodologies used in the chapter. Section 4 explains 
the measure of the surprise (unanticipated) element of the policy action. Section 5 presents data and empirical results, while the final section concludes.

\section{Literature review}

Previous literature has examined the effect of monetary policy shocks on stock returns both in terms of their mean and volatility effects.

These studies can be classified into two types. First, there are studies examining the effect of monetary policy on domestic stock markets, which are the most common. For instance, Bernanke and Kuttner (2005) analyse the impact of changes in US monetary policy on US equity prices using a VAR technique, with the objectives of both measuring the average reaction of the stock market and also understanding the economic sources of that reaction. They find that a cut in the federal funds rate target is associated with an increase in stock index. Gregoriou et al. (2006) examine the impact of UK monetary policy announcements on UK sectoral stock returns using a panel GMM estimator method. They find that monetary changes significantly impact stock returns. Hewson and Bonga-Bonga (2005) study the effects of monetary policy shocks in South Africa on different asset returns using a structural VECM. They find that the influence of monetary policy on stock returns as a result of interest rate changes is very small. The authors argue that since monetary policy changes can be anticipated easily, monetary policy changes appear to have an almost insignificant effect on stock prices.

Second, there are studies investigating the effect of monetary policy on foreign stock markets. Hausman and Wongswan (2011) study the response of global equity indexes in 16 countries, covering both developed and emerging markets, to the US monetary policy announcements. He finds a large and significant response of Asian, European, and Latin American equity indexes to US monetary policy announcement surprises.

Bredin et al. (2005) investigate the influence of US monetary policy announcements on the volatility of the Irish stock market. They find that there is a decline in volatility on the day prior to a FOMC meeting and a subsequent increase in volatility after the results of the FOMC meeting are made known. Conover et al. (1999) examine the relationship between US monetary conditions and international stock returns in a number of developed countries. They find that foreign stock markets exhibit similar patterns as the US market in that stock returns are higher in expansive monetary environments than they are in restrictive environments. Foreign stock returns are also related to the US monetary environment as many foreign markets exhibit significantly higher returns when the Federal Reserve is following an expansive versus a restrictive policy. They also found evidence that several stock markets are more strongly related to the US monetary environment than to local monetary conditions.

A different array of literature distinguished between the influences an expected monetary shock versus surprise monetary shock. The expected monetary shock is fixed in the calendar and is known to people in advance and does not impart new information on its own. In most studies, this component seems to have insignificant effects on stock market prices and returns (Conover et al., 1999; Bernanke and Kuttner, 2005; Bredin et al., 2005; Hausman and Wongswan, 2011). However, Gregoriou et al. (2006) find that both the expected and unexpected components of monetary changes significantly impact stock returns, but that only the surprise term is significant when he controls for the impact of the sectors' financial positions. 
On the other hand, the surprise monetary shock may impart new information as it may differ from what had been anticipated. Many studies such as Bernanke and Kuttner (2005) and Bredin et al. (2005) argue that if the markets are efficient, a financial asset should react only to the unanticipated element of the announcement. Therefore, market returns should not respond to the expected component of announcements.

Flannery and Protopapadkis (2002) find that only money supply surprises affect both the mean and variance of the US stock returns and volatility. Ehrmann and Fratzscher (2004) find that US equity returns react more strongly to US monetary policy shocks when changes by the FOMC are unexpected and when there is a directional change in the monetary policy stance of the Federal Reserve Bank (Fed). Bernanke and Kuttner (2005) find that the effects of the unanticipated US monetary policy actions on expected returns in the US stock market account for the largest part of the response of stock prices. Hausman and Wongswan (2011) find that foreign equity markets in both developed and emerging economies respond to FOMC announcements, and they respond mainly to the target surprise. He also finds evidence that equity markets incorporate news about US monetary policy surprises very quickly. And in a very interesting study, Connolly and Wang (2002) examine the influence of the surprise element in six macro series on stock returns between the USA, UK, and Japan. They find evidence that suggests that foreign news is likely to be more important than domestic news in explaining domestic stock market volatility. This finding is supported by Conover et al. (1999).

Previous literature also reported the possibility of asymmetry where the effect of (unexpected) negative shock is different from the effect of (unexpected) positive shock.

Bredin et al. (2005) argue that Irish stock return volatility is influenced by the US shock and the response is asymmetric. A negative policy surprise, which is lower than an expected policy rate change, reduces stock market volatility by significantly more than a positive surprise. Bonfim (2003) finds that unanticipated increases in the Fed funds' target rate have more influence on S\&P volatility than an unanticipated decrease. Conover et al. (1999) suggest that foreign stock markets in selected developed economies exhibit significantly higher returns when the Federal Reserve is following an expansive versus a restrictive policy. Connolly and Wang (1998) find that volatility spillover between the USA, UK, and Japan depends on whether the announcement imparts expansionary or contractionary information. In fact, contractionary monetary policy for the UK and USA was found to cause significant increases in volatility in Japan.

In the previous literature presented above, emerging stock market volatility due to US monetary shock has been studied recently by Hausman and Wongswan (2011). However, despite the growing interest in the region, the Middle East and North Africa (MENA) stock market has not been studied before. As a result, this paper will investigate the effect of US monetary policy shocks on the emerging MENA stock market.

\section{Methodology}

This paper adopts the following model which draws on the recent work of Anderson and Bollerslev (1998), Jones et al. (1998), Bonfim (2003) and Bredin et al. (2005). The rationale behind adopting the following model is that it considers the presence of the $\mathrm{ARCH}(\mathrm{GARCH})$ effect in the data. The model is as follows:

$$
\Delta C A S E_{t}=\beta_{0}+\beta_{1} \Delta F F F_{t-1}+\beta_{2} \Delta C A S E_{t-1}+\beta_{3} S \& P_{t-1}+u_{t}
$$




$$
\begin{aligned}
& u_{t}=e_{t}\left(s_{t}\right)^{1 / 2} \\
& e_{t}=v_{t}\left(h_{t}\right)^{1 / 2} \\
& E\left(e_{t} \mid \Omega_{t-1}\right)=0 \quad E\left(e_{t}^{2} \mid \Omega_{t-1}\right)=h_{t} \quad E\left(u_{t}^{2} \mid \Omega_{t-1}\right)=s_{t} h_{t} \\
& h t=\alpha_{0}+\alpha_{1} h_{t-1}+\alpha_{2} e_{t-1}^{2}
\end{aligned}
$$

The dependent variable in the conditional mean equation is the one-day percentage change in the Egyptian stock market, Cairo stock exchange (CASE) index. Since there is non-synchronisation in the trading times between both the Egyptian and the Israeli markets from one side and US market from the other side, the change in the CASE index must take into account the time difference between the USA and Egypt. Hence, $\triangle C A S E_{t}$ is defined as the one-day percentage change between $t-1$ and $t$ in the CASE index. The independent variables include the one-day change in both the federal funds futures $(\triangle \mathrm{FFF})$, and the S\&P $500(\mathrm{~S} \& \mathrm{P})^{1}$ and are consequently dated from $t-1$ to $t$. For completeness, the lagged one-day percentage change in the CASE is included. The lagged variable is important as it hosts past information regarding the factors affecting MENA stock market whether they are of a domestic, regional, or international nature. Lastly, $u_{t+1}$ is the unexplained element of MENA (Egyptian or Israeli) stock returns.

The unexplained element can be thought of as comprising a non-normal stochastic element, $e_{t+1}$, whose conditional variance is time varying and $s_{t+1}$, a dummy to indicate the impact of particular day effects. The $s_{t+1}$ dummy can be written as:

$$
s_{t+1}=1+\delta_{0} I_{t}^{(F)}+\delta_{1} I_{t-1}^{(F)}+\delta_{2} I_{t+1}^{(F)}
$$

Where $I_{t}^{(F)}$ is a dummy variable set to one on days when there is a regularly scheduled US Federal Reserve policy meeting and zero elsewhere. The focus is on three issues. First, does CASE volatility follow a pattern at which volatility is lower on a day prior to FOMC meetings and higher on the day of the announcement? In equation (6), a finding of a lower volatility before a meeting would be evident if the efficient $\delta_{1}$ was negative and statistically significant, while $\delta_{0}$ was positive and statistically significant. Secondly, it examines whether there is any news effect, i.e., whether a 'surprise change' in the federal funds rate target has an effect on CASE returns. This would be reflected in a negative statistically significant value for the coefficient $\beta_{1}$. Finally, it tests whether the news effect has any influence on CASE volatility (Bredin et al., 2005).

The above methodology is repeated for both Israel and Turkey, at which the general form of the conditional equation will be as follows:

$$
\Delta M E N A_{t}=\beta_{0}+\beta_{1} \Delta F F F_{t-1}+\beta_{2} \Delta M E N A_{t-1}+\beta_{3} S \& P_{t-1}+u_{t}
$$

The models will be estimated using the quasi maximum likelihood procedure outlined in Bollerselv and Wooldridge (1992).

It should be noted that dividends are excluded from this model, even though they can host some monetary effect. This is not only because of data unavailability bust also because it is unlikely to make a significant difference as they are very smooth. This might affect the intercept (mean) across assets but not the comovement.

Note also that the study relies on the assumption that the error term is orthogonal to federal funds rate changes. One reason for the violation of this condition would be a 
contemporaneous response of monetary policy to the MENA stock markets. There is, however, no evidence of such an action in which a drop in an international stock market index, notably in the MENA region, led FOMC to cut rates, or the inverse.

\section{Unanticipated shock}

In terms of the proxy for the surprise element in monetary policy decisions included in the mean equation (1), I will use a technique proposed by Kuttner (2001) and Bernanke and Kuttner (2005), which uses federal funds futures data to construct a measure of 'surprise' rate changes, which can be derived from the change in the futures contract's price relative to the day prior to the policy action. Specifically, the 'surprise' target rate change can be calculated as the change in the 'spot month' (i.e., for the month in which the target is changed) Fed funds futures rate on the day of the rate change, scaled up by a factor related to the number of days in the month affected by the change,

$$
\Delta \hat{i}_{t}^{u}=\frac{m}{m-t}\left(f_{s, t}^{o}-f_{s, t-1}^{o}\right)
$$

where $\hat{i}^{u}$ is the unexpected target rate change, $f_{s, t}^{o}$ is the spot-month futures rate on day $t$ of month $s$, and $m$ is the number of days in the month. The expected component of the rate change is simply defined as the actual minus the surprise, or

$$
\Delta \hat{i}_{t}^{e}=\Delta \hat{i}_{t}-\Delta \hat{i}_{t}^{u} .
$$

\section{Data and empirical results}

This study uses daily closing prices from January 2, 1997, through June 28, 2007, for S\&P500, CASE30 (CASE), TASE100 (Tel Aviv stock exchange), and ISE100 (Istanbul stock exchange), which are taken from Datastream. The sample ends in the middle of 2007 to avoid any significant distortion that might occur in the empirical results due to 2008 financial crisis.

The actual change in the federal funds rate is obtained from the Federal Reserve Board of Governors. The unanticipated change in the federal fund target rate is proxied by the one day change in the price of the month preceding 30-day Federal Fund Future Contract, as traded on the Chicago Board of Trade (CBOT).

Note that the use of the daily closing prices to calculate the returns (close-to-close returns) include information accumulated overnight which is a period that overlaps with US market opening. This issue will not be a great concern to us for different reasons. First, the aim of the paper is not to investigate the spillover over among two different stock markets at which returns frequently change. However, the paper objective is to test the influence of the US monetary policy shocks as represented by the change in the federal funds on the volatility in the MENA markets. These changes in the federal funds rate occur infrequently (only 22 times during the period of study). Most importantly, empirical evidence such as Hayford and Malliaris (2004) acknowledged that the Fed under Greenspan have never responded to the NYSE overvaluation. This also implies that 
the Federal Reserve did not react to international stock markets notably the small ones such as MENA stock markets.

\subsection{Empirical results}

\subsubsection{GARCH $(1,1)$ specification}

Because the VAR approach does not consider the presence of the ARCH (GARCH) effect in the data, the paper adopts a GARCH technique in order to account for ARCH effect. Including the previous period returns in the MENA market along with the return in the New York stock exchange (S\&P) in a GARCH context will give a broader view about the causes of volatility in MENA stock markets.

Consequently, the paper adopts a GARCH specification, stated in equations (1) through (6), where the model will be estimated using the quasi maximum likelihood procedure.

In the conditional mean equation, the $\Delta \mathrm{FFF}$ is the change in the federal fund target rate; no restriction is made here about that change whether it is a result of a scheduled or unscheduled meeting.

Table 1 Estimates for GARCH $(1,1)$ specification

\begin{tabular}{|c|c|c|c|}
\hline \multirow{2}{*}{ Variable } & Egypt & Israel & Turkey \\
\hline & Coeff. & Coeff. & Coeff. \\
\hline Mean equation & \multicolumn{3}{|c|}{$\Delta M E N A_{t}=\beta_{0}+\beta_{1} \Delta F F F_{t-1}+\beta_{2} M E N A_{t-1}+\beta_{3} S \& P_{t-1}+u_{t}$} \\
\hline$\beta_{0}$ & 0.097 & 0.109 & 0.622 \\
\hline$\beta_{1}$ & $-0.053^{*}$ & -0.011 & -0.171 \\
\hline$\beta_{2}$ & $0.054^{*}$ & 0.024 & 0.029 \\
\hline$\beta_{3}$ & -0.002 & -0.002 & 0.009 \\
\hline Variance equation & \multicolumn{3}{|c|}{$h t=\alpha_{0}+\alpha_{1} h_{t-1}+\alpha_{2} e_{t-1}^{2}$} \\
\hline$\alpha_{0}$ & $0.008^{*}$ & $0.201 *$ & $3.434 *$ \\
\hline$\alpha_{1}$ & $0.084^{*}$ & $0.057^{*}$ & $0.095 *$ \\
\hline$\alpha_{2}$ & $0.919 *$ & $0.91 *$ & $0.900 *$ \\
\hline
\end{tabular}

Note: *Significant at $5 \%$ level.

Table 1 shows that US monetary policy has influence only on Egypt but not Israel and Turkey. The change in the federal funds rate has a negative significant effect on the CASE returns. The federal funds rate has also a negative sign for both TASE and ISE but not significant. The variance equation shows that $\alpha_{1}$ and $\beta_{1}$ for all three countries almost add up to one. This indicates that volatility is persistence in MENA stock markets which is rather similar to the developed markets pattern.

The paper next decomposes the change in the federal funds target rate in the conditional mean equation into surprise and expected changes as follows:

$$
\Delta M E N A_{t}=\beta_{0}+\beta_{1} \Delta F F F_{t-1}^{u}+\beta_{2} \Delta F F F_{t-1}^{e}+\beta_{3} \Delta M E N A_{t-1}+\beta_{4} S \& P_{t-1}+u_{t}
$$


This step also serves as a robustness check for the influence of the monetary shock on stock returns in the three selected markets.

Table 2 Estimates of GARCH model for expected and unexpected change

\begin{tabular}{|c|c|c|c|}
\hline \multirow{2}{*}{ Variable } & Egypt & Israel & Turkey \\
\hline & Coeff. & Coeff. & Coeff. \\
\hline \multicolumn{4}{|c|}{ Mean equation } \\
\hline$\beta_{0}$ & -0.0216 & 0.1167 & 0.1177 \\
\hline$\beta_{1}$ & 0.0119 & -0.0333 & -0.1236 \\
\hline$\beta_{2}$ & $-0.5719 *$ & 0.6819 & 5.2427 \\
\hline$\beta_{3}$ & $-0.5719 *$ & 0.0334 & 0.0301 \\
\hline$\beta_{4}$ & -0.0004 & -0.0016 & 0.0092 \\
\hline \multicolumn{4}{|c|}{ Variance equation } \\
\hline$\alpha_{0}$ & 0.0920 & $0.2025^{*}$ & $3.3619^{*}$ \\
\hline$\alpha_{1}$ & 2.4406 & $0.0576^{*}$ & $0.0944 *$ \\
\hline$\alpha_{2}$ & $0.8703 *$ & 0.9093* & $0.9013 *$ \\
\hline
\end{tabular}

Note: *Significant at $5 \%$ level.

The results in Table 2 show that the expected change in the federal funds rate has a negative significant sign for Egypt while the unexpected shock has a positive non-significant coefficient suggesting that the returns in Egypt's stock market only respond to the expected shocks. It should be noted that the monetary shock in equation (10), though significant, but has a very modest effect on the returns in Egypt. On the other hand, US monetary policy changes, whether expected or unexpected, do not influence Istanbul's and Israeli's stock markets.

The efficient market hypothesis claims that the response of the stock market to the expected component of the monetary policy should be minimal. The results for Egypt contradict the efficient market proposition implying that the CASE is not an efficient market.

In fact, the results recommend that US monetary policy affects stock prices in Egypt significantly by affecting stock returns, i.e., tight monetary policy lowers the stock markets returns. This could come about as mentioned by Bernanke and Kuttner (2005) in at least two ways. First, tight monetary policy could increase the riskiness of stocks directly, for example, by raising the interest costs or weakening the balance sheets of publicly owned firms. Second, tight monetary policy could reduce the willingness of stock investors to bear risk, for example by reducing the expected level of consumption, or because of its association with higher inflation.

According to Azzab (2002), Egypt's market is generally characterised by being 'informationally inefficient', which might indicate the existence of mispricing opportunities that justify the activities of active fund management to achieve abnormal returns within these markets. He argues that the Egyptian market shows persistent positive trend which has caused average cumulative abnormal returns to increase at a steady rate during the period. A possible explanation for this behaviour is that there might have been an information leakage about the intended acquisitions well before the announcement date. This has caused abnormal returns to be positive days before the 
announcement date. Furthermore, The fact that the Egyptian stock exchange imposes a price limit on the maximum and minimum the price of a security can reach in a day (plus or minus $5 \%$ of closing price of the previous day), may have caused the slow adjustment of the securities' prices to their new fair values and, therefore, caused the increasing cumulative abnormal returns after the announcement date.

The above paragraph points out to the intuition behind the relationship but not the channel through which the US monetary policy shocks influence the Egyptian stock market. Strong trade links between Egypt and the USA might not be enough to explain the relationship as these trade links is the same for Israel. One viable explanation is the exchange rate regime in Egypt. During the period of study, Egypt adopted two different exchange rate regimes, Crawling peg exchange rate regime against the US dollar and managed float exchange rate regime. Those two different regimes gave up the control of the domestic monetary policy in order to defend the desired value of the Egyptian pound, resulting in giving more influence to the US monetary policy on the macroeconomic domestic variables in Egypt. As documented in the literature, external shocks appear to have a greater influence on fluctuations of macroeconomic variables in fixed exchange rate regimes than floating exchange rate regimes, because the exchange rate does not buffer those countries from external shocks. The findings of the study come in line with Desroches (2004), who argues that the type of exchange rate regime is a critical determined for the transmission of external shocks. His study concludes that countries under flexible exchange rate regimes are less likely to be influenced by foreign shock than those countries with fixed exchange rate regime.

Israel and Turkey, on the other hand, have a flexible exchange rate regime which makes their own monetary policies more effective than the foreign monetary policy.

\subsubsection{Robustness check}

In this section, we check the robustness of the results to excluding the monetary policy surprise shock. Equation (11), where the unexpected monetary shock is dropped out, will be estimated using GARCH $(1,1)$ technique. The results are provided in Table 3.

$$
\Delta M E N A_{t}=\beta_{0}+\beta_{2} \Delta F F F_{t-1}^{e}+\beta_{3} \Delta M E N A_{t-1}+\beta_{4} S \& P_{t-1}+u_{t}
$$

Table 3 Estimates of GARCH model excluding surprise shock

\begin{tabular}{lcccc}
\hline \multirow{2}{*}{ Variable } & Egypt & & Israel & Turkey \\
\cline { 2 - 3 }$\beta_{0}$ & Coeff. & Coeff. & Coeff. \\
$\beta_{2}$ & -0.0211 & & \\
$\beta_{3}$ & $0.5684^{*}$ & $0.0708^{*}$ & 0.1165 & 0.1177 \\
$\beta_{4}$ & -0.0004 & 0.6855 & 5.2357 \\
Variance equation & & 0.0329 & 0.0301 \\
$\alpha_{0}$ & 0.0891 & -0.0015 & 0.0096 \\
$\alpha_{1}$ & 2.3913 & & \\
$\alpha_{2}$ & $0.8711^{*}$ & & $0.2008^{*}$ & $3.3586^{*}$ \\
\hline
\end{tabular}

Note: *Significant at $5 \%$ level. 
The results in Table 3 support the findings in the previous section. That is, the results are robust to excluding the surprise monetary policy. The expected monetary shock and the own lag returns remain significant for the stock markets in Egypt while they remain non-significant for stock markets in Israel and Turkey. Moreover, the results of the variance equation are also robust to the exclusion of the surprise shock. They indicate that volatility in the MENA markets is persistent.

\subsection{Calm before the storm}

In the financial press, there is anecdotal evidence to suggest that markets enter a lull prior to the release of important information. In the wake of an announcement, traders react to such information leading to an increase in activity. This pattern has been dubbed "the calm before the storm" (Bredin et al., 2005). Thus, the paper turns to investigate whether there are any pre-announcement effects in MENA stock markets. To properly assess the importance of such pre-announcement effects, it is useful again to distinguish between scheduled meeting days and days when the change in rate was unscheduled. For our sample period, there are only five unscheduled meetings, four of which are in 2001, and 104 scheduled meetings.

We will modify the variance equation to distinguish between scheduled and unscheduled meeting days:

$$
s_{t+1}=1+\delta_{0} I_{t-1}^{S}+\delta_{2} I_{t+1}^{S}+\delta_{3} I_{t}^{S}+\delta_{4} I_{t-1}^{U}+\delta I_{t+1}^{U}
$$

where $I^{S}$ is a dummy variable, equal to one, for scheduled FOMC meetings and $I^{U}$ is a dummy variable equal to one when there are no scheduled meetings. The above equation will be tested only for Egypt since the methodologies used in this paper proved that there is no spillover of monetary shocks from the USA to Israel and Turkey.

Table 4 Estimates of GARCH for scheduled and unscheduled meetings

\begin{tabular}{lc}
\hline Variable & Egypt \\
\cline { 2 - 3 } & Coeff. \\
\hline Mean equation & \\
$\beta_{0}$ & 0.04541 \\
$\beta_{1}$ & $-0.13276^{*}$ \\
$\beta_{2}$ & $0.05528^{*}$ \\
$\beta_{3}$ & $0.00841^{*}$ \\
Variance equation & \\
$\alpha_{0}$ & 0.02765 \\
$\alpha_{1}$ & $0.09086^{*}$ \\
$\alpha_{2}$ & $0.63544^{*}$ \\
$\delta_{0}$ & $-0.11842^{*}$ \\
$\delta_{2}$ & $-0.56405^{*}$ \\
$\delta_{3}$ & 0.50087 \\
$\delta_{4}$ & -1.73218 \\
$\delta_{5}$ & 1.77401 \\
\hline
\end{tabular}

Note: *Significant at $5 \%$ level. 
Table 4 reports the new specification of the GARCH model where the results for Egypt support the conventional argument that there is a reduction in volatility prior to the announcement (FOMC scheduled meeting), i.e., $\delta_{0}$ is significantly negative; while there is an absence of such an effect prior to the unscheduled rate change $\left(\delta_{4}\right.$ is insignificant). Since unscheduled rate change is by definition unknown to market participants, one may not expect to see calm in the market before the announcement. This calm is experienced by Egypt's market only before a regular meeting because market participants, in this case, wait for the announcement before they react to it.

\section{Conclusions}

This paper examines the effect of US monetary policy shocks on stock markets returns and volatility in international stock markets in Egypt, Israel, and Turkey for the period from 1996 through 2007. In particular, investigating the influence of surprise and expected change in the monetary policy on these markets. The study employs a multivariate GARCH techniques to capture the mechanism by which the US monetary shock, as indicated as either a change in the federal funds rate, or FOMC meeting, influence the conditional stock market returns and volatility of the MENA markets. The results indicate that Egypt stock market exhibit similar pattern as the US market in that the stock returns are higher in expansive monetary environments than they are in restrictive environment. This comes in line with the results of Conover et al. (1999). The US monetary policy changes, however, do not influence stock market returns in both Israel and Turkey. The paper argues that the absence of the US monetary influence in Israel and Turkey while its presence in Egypt is mainly due to the differences in the exchange rate regimes adopted in these countries.

The paper proceeds to decompose the effect of monetary policy shocks into expected and surprise shocks. This step not only serves as a robustness check for the results but also a method to check for the efficiency of MENA stock markets. The findings confirm those of the first regression, where the US monetary policy tends to have an impact only on Egypt's stock market. The findings also indicate that the stock market in Egypt only responds to the anticipated changes in the monetary policy and not to the surprise changes, which contradict the efficient market hypothesis. This is due to the limitation that is imposed by the stock exchange in Egypt on the daily price movements which is plus or minus 55 of the previous day closing prices. This has a significant effect on the speed of price adjustment of the stocks to their new fair values, which provide opportunities for uninformed investors to profit from trading by simply observing the price behaviour without any analytical effort. Therefore, the issue of having a price limit should be re-evaluated by the exchange for the possible abolition. This should have the effect of reducing uninformed market speculation, which has resulted in inflating the prices of securities without any fundamental support on several occasions in the past.

The findings from this study have implications for investment portfolio formation. Market participants, notably in Egypt, should be aware of the relationship between the US monetary policy decisions and stock market performance. The results, for instance, indicate that the US monetary policy should be considered when analysing international diversification opportunities. Conover et al. (1999) argue that although the benefits of international diversification have been widely touted, incorporating the monetary environment into decisions may allow investors to benefit more fully from such efforts. 


\section{References}

Anderson, T. and Bollerslev, T. (1998) Testing for Market Microstructure Effects on Intraday Volatility: A Reassessment of the Tokyo FX Experiment, NBER Working Paper \# 6666, National Bureau of Economic Research.

Azzab, B. (2002) The Performance of the Egyptian Stock Market, The University of Birmingham Master's thesis, unpublished.

Bernanke, B. and Kuttner, K. (2005) 'What explains the stock market reaction to Federal Reserve policy', Journal of Finance, Vol. 60, No. 3, pp.1221-1257.

Bollerselv, T. and Wooldridge, J. (1992) Quasi Maximum Likelihood Estimation of Dynamic Models with Time-Varying Covariances, MIT Working Paper \# 505, Massachusetts Institute of Technology.

Bonfim, A. (2003) 'Pre-announcement effects, new effects and volatility: monetary policy and the stock market', Journal of Banking and Finance, Vol. 27, No. 2, pp.133-151.

Bredin, D., Gravin, C. and O'Reilly, G. (2005) 'U.S. monetary policy announcements and Irish stock market volatility', Applied Financial Economics, Vol. 15, No. 1, pp.1243-1250.

Connolly, R. and Wang, F. (1998) 'Economic news and stock market linkages: evidence from U.S., U.K, and Japan', Proceedings of the Second Joint Central Bank Research Conference on Risk Management and Systemic Risk, Vol. 1, pp.211-240.

Connolly, R. and Wang, F. (2002) 'International equity market comovements: economic fundamentals or contagion', Pacific Basin Finance Journal, Vol. 11, No. 1, pp.23-43.

Conover, C., Jensen, G. and Johnson, R. (1999) 'Monetary environment and international stock returns', Journal of Banking and Finance, Vol. 23, No. 2, pp.1357-1381.

Desroches, B. (2004) The Transmission of World Shocks to Emerging Market Countries: An Empirical Analysis, Bank of Canada Working Paper No. 44.

Ehrmann, M. and Fratzscher, M. (2004) Taking Stock: Monetary Policy Transmission to Equity Markets, Working Paper Series \# 0354, European Central Bank.

Flannery, M. and Protopapadkis, A. (2002) 'Macroeconomic factors do influence aggregate stock returns', Review of Financial Studies, Vol. 15, No. 3, pp.751-782.

Gregoriou, A., Kontonikas, A., MacDonald, R. and Montagnoli, A. (2006) 'Monetary policy shocks and stock returns: evidence from the British market', Financial Markets and Portfolio Management, Vol. 23, No. 4, pp.401-410.

Halicioglu, F. (2007) 'The J-curve dynamics of Turkish bilateral trade: a cointegration approach', Journal of Economic Studies, Vol. 34, No. 2, pp.103-119.

Hausman, J. and Wongswan, J. (2011) 'Global asset prices and FOMC announcements', Journal of International Money and Finance, Vol. 30, No. 3, pp.547-571.

Hayford, M. and Malliaris, A. (2004) 'Monetary policy and the U.S. stock market', Economic Inquiry, Vol. 42, No. 3, pp.387-401.

Hewson, M. and Bonga-Bonga, L. (2005) The Effects of Monetary Policy Shocks on Stock Returns in South Africa: A Structural Vector Error Correction Model, University of Johannesburg.

Jones, M., Lamont, O. and Lumsdaine, R. (1998) 'Macroeconomic news and bond market volatility', Journal of Financial Economics, Vol. 47, No. 1, pp.315-337.

Kuttner, K. (2003) Dating Changes in the Federal Funds Rate, 1989-1992, Federal Reserve Bank of New York, Working paper, Oberlin College.

\section{Notes}

1 The use of S\&P 500 is common in the literature studying the same issue. 